Supplemental Information for

\title{
Secondary organic aerosol formation and primary organic aerosol oxidation from biomass burning smoke in a flow reactor during FLAME-3
}

\author{
A. M. Ortega ${ }^{1,2}$, D. A. Day ${ }^{1,3}$, M. J. Cubison ${ }^{1,3}$, W. H. Brune ${ }^{4}$, \\ D. Bon ${ }^{1,3,5}$, J. de Gouw ${ }^{1,5}$, and J. L. Jimenez ${ }^{1,3}$ \\ ${ }^{1}$ Cooperative Institute for Research in the Environmental Sciences, Boulder, CO, USA \\ ${ }^{2}$ Department of Atmospheric and Oceanic Science, University of Colorado, Boulder, CO, USA \\ ${ }^{3}$ Department of Chemistry and Biochemistry, University of Colorado, Boulder, CO, USA \\ ${ }^{4}$ Department of Meteorology, Pennsylvania State University, University Park, PA, USA \\ ${ }^{5}$ Chemical Sciences Division, NOAA Earth System Research Laboratory, Boulder, CO, USA
}

\section{Discussion of Figure S3.}

The standard AMS fragmentation table is the foundation for calculating OA mass in ambient AMS measurements (Allan et al., 2004). Unlike typical ambient observations, OA dominated

the total aerosol mass spectra (campaign averaged, OA was 93\% of total aerosol). Hence, the standard fragmentation table needed to be adjusted to account for high organic-mass loadings (see Fig. S3). In this modification, sulfate was treated as interference on the organic peaks, as opposed to organic as an interference on the sulfate peaks, as in the default treatment of the “ambient” fragmentation table. To accomplish this, $m / z 48$ was the basis for estimating the sulfate contribution as the ratio of dominant ions at $\mathrm{m} / \mathrm{z} 48, \mathrm{C}_{4}{ }^{+}$and $\mathrm{SO}^{+}$, was constant with OA mass. See Table S1 for the modified fragmentation table and Fig. S3.

\section{Figure Captions:}

Table S1. Standard AMS fragmentation table for unit mass resolution (UMR) analysis and updated table for calculating sulfate and organic mass fragments for biomass burning smoke measurements with high organic fraction of total aerosol mass. 
Fig. S1: Photo of (a) Fire Sciences Laboratory's (FSL) fire chamber in open/chamber burn configuration for burn 58, saw grass, taken by Dan Bon, (b) PAM reactor in open flow through configuration with both lamps on, taken by Amber Ortega.

Fig. S2: Sawtooth pattern from switching OA measurements (light lines) between aged (dashed lines) and unprocessed (solid lines) sampling for organic aerosol and aerosol markers: oxidation ( $\mathrm{m} / \mathrm{z} 44$, pink lines) and primary biomass burning ( $\mathrm{m} / \mathrm{z} 60$, brown lines) for two burns, turkey oak (burn 45) and ponderosa pine (burn 40). Tags indicate typical operations, such as changes in $\mathrm{OH}$, filters, and sampling.

Fig. S3. A procedure developed to correctly calculate sulfate and organic concentrations for biomass burning smoke. The top left plot is the ratio of $\mathrm{C}_{4}{ }^{+}$to $\mathrm{SO}^{+}$at $\mathrm{m} / \mathrm{z} 48$ vs. unprocessed OA mass, colored by $\mathrm{SO}^{+}$ion signal for three fuels (ponderosa pine, burn 40; lodgepole pine burn 50; and turkey oak, burn 45). The rest of the plots compare standard fragmentation table calculations of sulfate to the updated biomass burning specific UMR fragmentations table (see Table S1) for burn 42, wire grass. The top right plot is a time series of sulfate from standard (labeled "Std Frag SQ”) and updated (labeled “BB Frag SQ”) calculations for UMR (red) and high-resolution (black) data. The bottom left plot is the mass spectra of sulfate from standard (labeled "Std Frag SQ”) and updated (labeled "BB Frag SQ”) calculations, and the bottom right plot is the sulfate mass spectra comparison of UMR (labeled "SQ") and high-resolution (labeled "PK") data for the standard (labeled “Std Frag SQ”) and updated (labeled “BB Frag SQ”).

Fig. S4. (a) Comparison of organic mass time series for all data from all burns of unit mass resolution to high-resolution analysis (as calculated up to $\mathrm{m} / \mathrm{z} 100$ ). (b) Cation balance with highresolution data, measured to predicted cations $\mathrm{K}^{+}$and $\mathrm{NH}_{4}{ }^{+}$based on neutral inorganic ion stoichiometry.

Fig. S5. Average high-resolution spectrum at $m / z 28$ averaged from 08:46:00-08:57:00 on 9/22/2009 during burn 42, wire grass for (a) aged and (b) unprocessed smoke.

Fig. S6. $\mathrm{OH}_{\mathrm{exp}}$ as calculated from offline $\mathrm{SO}_{2}$ calibrations versus $\mathrm{OH}_{\mathrm{ex}}$ calculated from real-time VOC decays with all data in light circles and stable data in dark circles for benzene (red) and toluene (blue).

Fig. S7. Evolution of aerosol ions at $m / z 28$ and $m / z 44$ from high-resolution analysis for two biomass fuels, turkey oak (burn 45) and ponderosa pine (burn 40), normalized to peak $\mathrm{CO}^{+}$and $\mathrm{CO}_{2}{ }^{+}$concentration in each burn. The saw-tooth pattern is the result of switching between aged and the unprocessed smoke sample.

Fig. S8. The mass spectra ratio, $\mathrm{ER}_{\mathrm{OA}}$, of aged to unprocessed smoke of two fuels: turkey oak, burn 45, and ponderosa pine, burn 40, where an increase in ion signal is shown in green (ER $\mathrm{OA}^{>}$ $1)$ and decrease in ion signal $\left(\mathrm{ER}_{\mathrm{OA}}<1\right)$ is shown in red. 
64 Fig. S9. Fractional contribution of oxidation and biomass burning tracers vs. POA concentration.

65 (a) $f_{44}$ vs. POA for unprocessed smoke from all burn experiments. (b) $f_{60}$ vs. POA for

66 unprocessed smoke from all burn experiments. (c) Aging effects on $f_{\mathrm{CO} 2}{ }^{+}$and biomass-burning

67 marker, $f_{60}$, for four select fuels (ponderosa pine, burn 40; wire grass, burn 42; turkey oak, burn

68 45; and sage, burn 49). Dotted lines are from ambient biomass burning measurements from

69 Cubison et al. (2011).

70 Fig. S10. Van Krevelen diagram, showing hydrogen-to-carbon (H/C) ratio vs. oxygen-to-carbon

71 ratio (O/C). (a) Six fuels (ponderosa pine, burn 40; pocosin, burn 41; wire grass, burn 42; turkey

72 oak, burn 45; sage, burn 49; and lodgepole pine, burn 61), with associated slopes from a linear

73 orthogonal distance regression fit. (b) All fuels, with associated slopes from a linear orthogonal

74 distance regression fit reported in legend (lines not shown for simplicity), slopes from Heald et

75 al. (2010; solid lines), ambient measurements of OOA data first presented in $f_{44} / f_{43}$ space in $\mathrm{Ng}$

76 et al. (2010) and transformed in to Van Krevelen space in Ng et al. (2011)'s work (dashed lines)

77 with shaded region (gray area) denoting $\pm 10 \%$ uncertainty. 


\section{Table S1.}

\section{Standard Frag Table for Unit Mass Resolution AMS Analysis}

\begin{tabular}{|c|c|c|c|c|}
\hline$m / z$ & frag_organic & frag_sulphate & frag_SO3 & frag_H2SO4 \\
\hline 48 & 0.5*frag_organic[62] & $\begin{array}{l}\text { frag_SO3[48], } \\
\text { frag_H2SO4[48] }\end{array}$ & $\begin{array}{c}\text { 48,-frag_organic[48],-frag_nitrate[48], } \\
\text {-frag_H2SO4[48] }\end{array}$ & $\begin{array}{l}.5 * .93 * \text { frag_H2SO4[81] } \\
.5 * .93 * \text { frag_H2SO4[98] }\end{array}$ \\
\hline 64 & 0.5*frag_organic[50],0.5*frag_organic[78] & $\begin{array}{l}\text { frag_SO3[64], } \\
\text { frag_H2SO4[64] }\end{array}$ & 64,-frag_organic[64],-frag_H2SO4[64] & $\begin{array}{c}0.5 * 0.93 * \text { frag_H2SO4[81], } \\
0.5 * 0.93 * \text { frag_H2SO4[98] }\end{array}$ \\
\hline 80 & 0.75*frag_organic [94] & $\begin{array}{l}\text { frag_SO3[80], } \\
\text { frag_H2SO4[80] }\end{array}$ & $0.25 * 80,-0.25 *$ frag_organic $[80]$ & $0.75 * 80,-0.75 *$ frag_organic $[80]$ \\
\hline 81 & 0.5*frag_organic[67],0.5*frag_organic[95] & frag_H2SO4[81] & & 81,-frag_organic[81] \\
\hline 98 & 0.5*frag_organic[84],0.5*frag_organic[112] & frag_H2SO4[98] & & 98,-frag_organic[98] \\
\hline
\end{tabular}

\section{Updated Frag Table for Unit Mass Resolution AMS Analysis}

\begin{tabular}{|c|c|c|}
\hline $\mathrm{m} / \mathrm{z}$ & frag_organic_BB & frag_sulphate_BB \\
\hline 48 & $\begin{array}{l}0.032 * 0.5 * \text { frag_organic_BB[47], } \\
0.032 * 0.5 * \text { frag_organic_BB[49] }\end{array}$ & 48,-frag_organic_BB[48] \\
\hline 64 & 64,-frag_sulphate_BB[64] & 1.14*frag_sulphate_BB[48] \\
\hline 80 & 80,-frag_sulphate_BB[80] & $0.32 *$ frag_sulphate_BB[48] \\
\hline 81 & 81,-frag_sulphate_BB[81] & $0.23 *$ frag_sulphate_BB[48] \\
\hline 98 & 98,-frag_sulphate_BB[98] & $0.124 *$ frag_sulphate_BB[48] \\
\hline
\end{tabular}




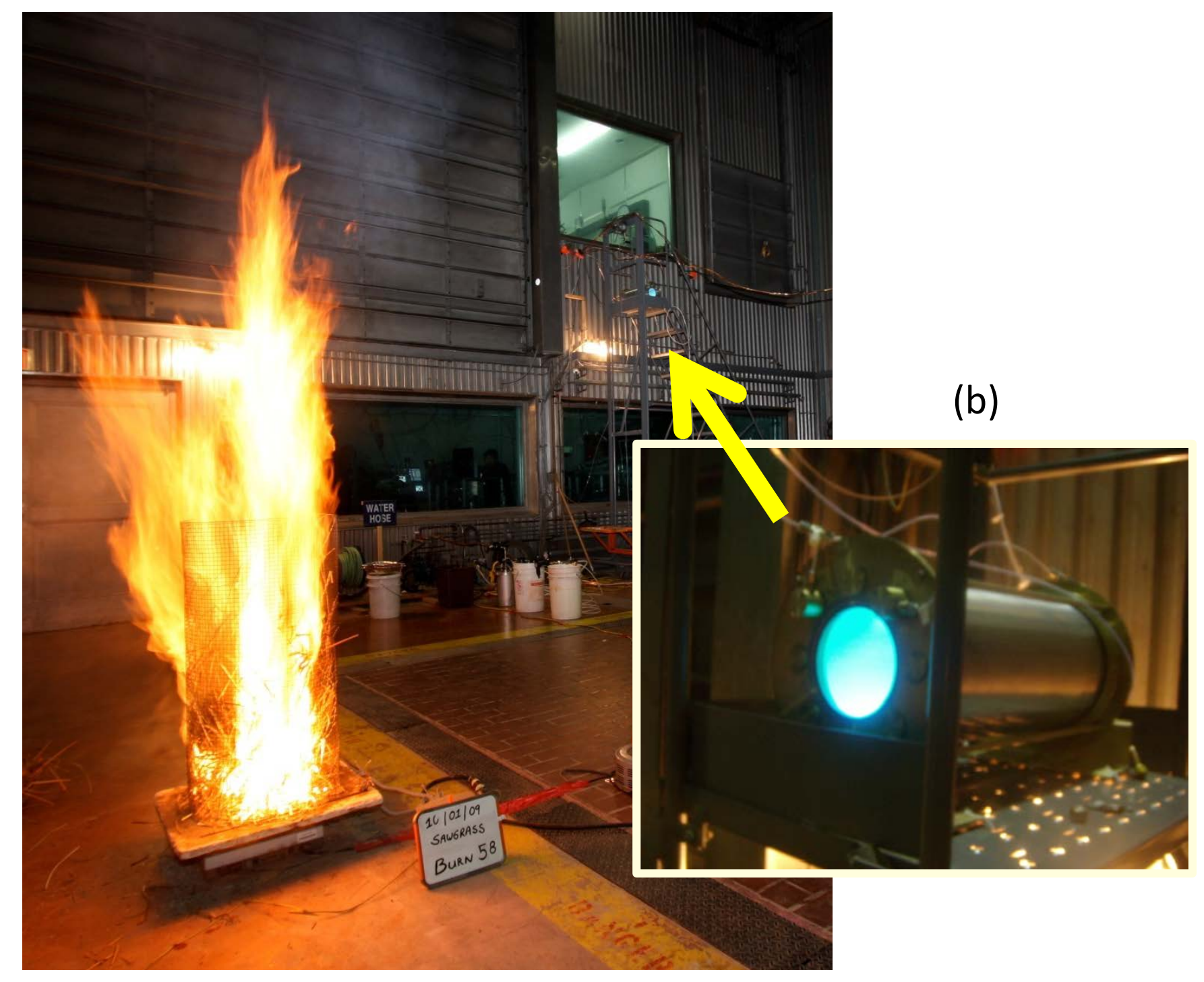

\section{Figure S1. \\ (a)}




\section{Figure S2.}
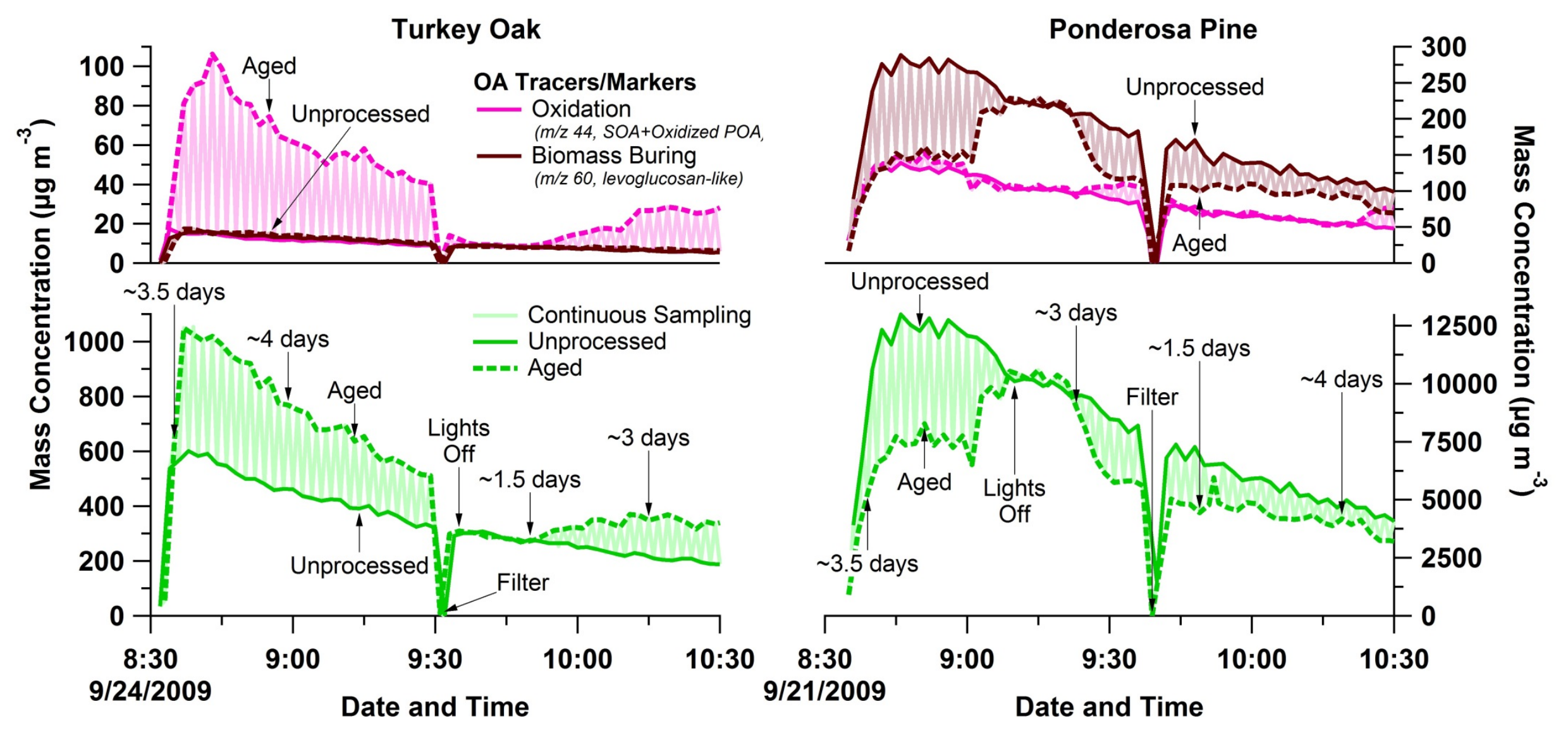


\section{Figure S3.}
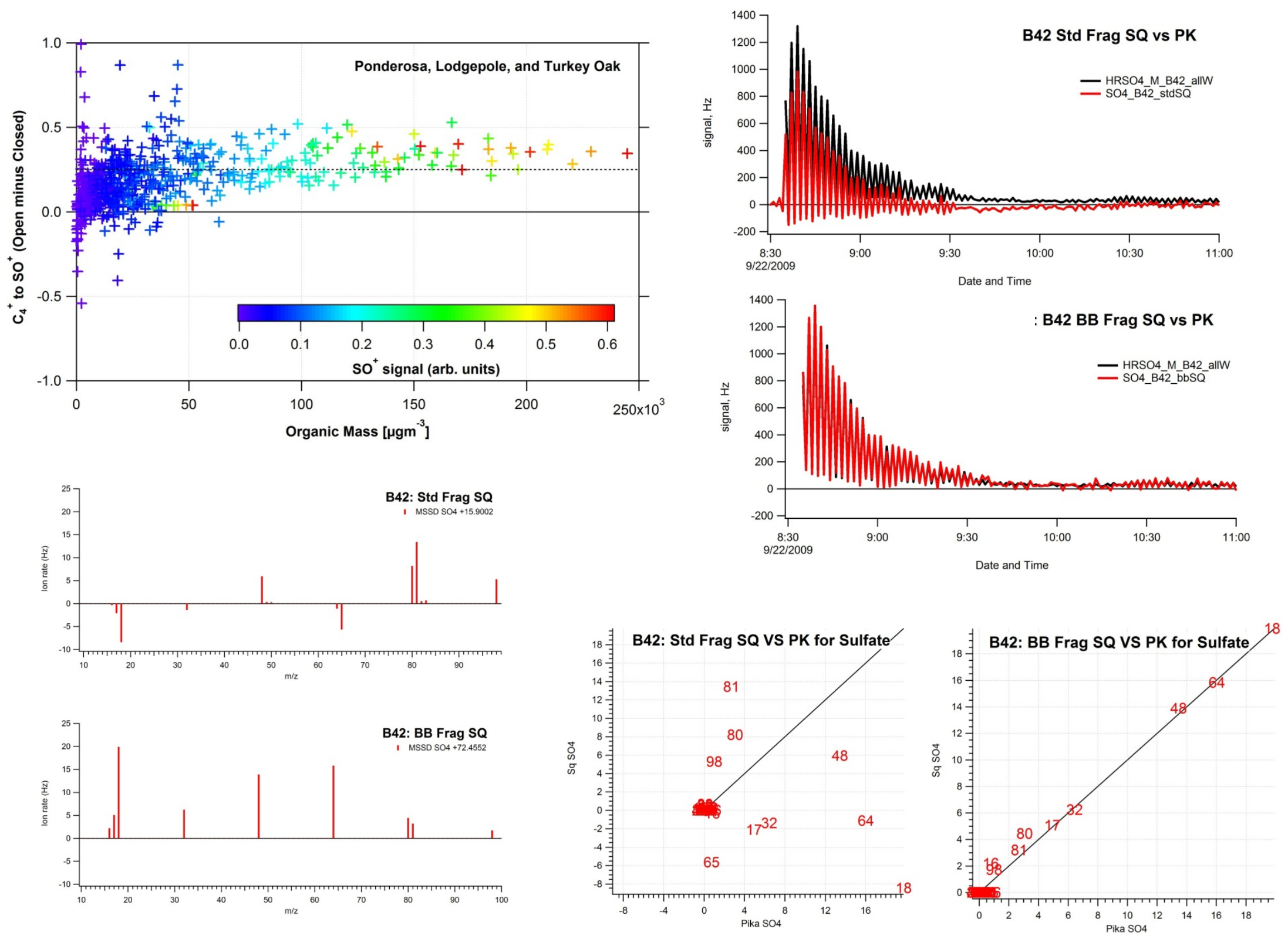
Figure S4.
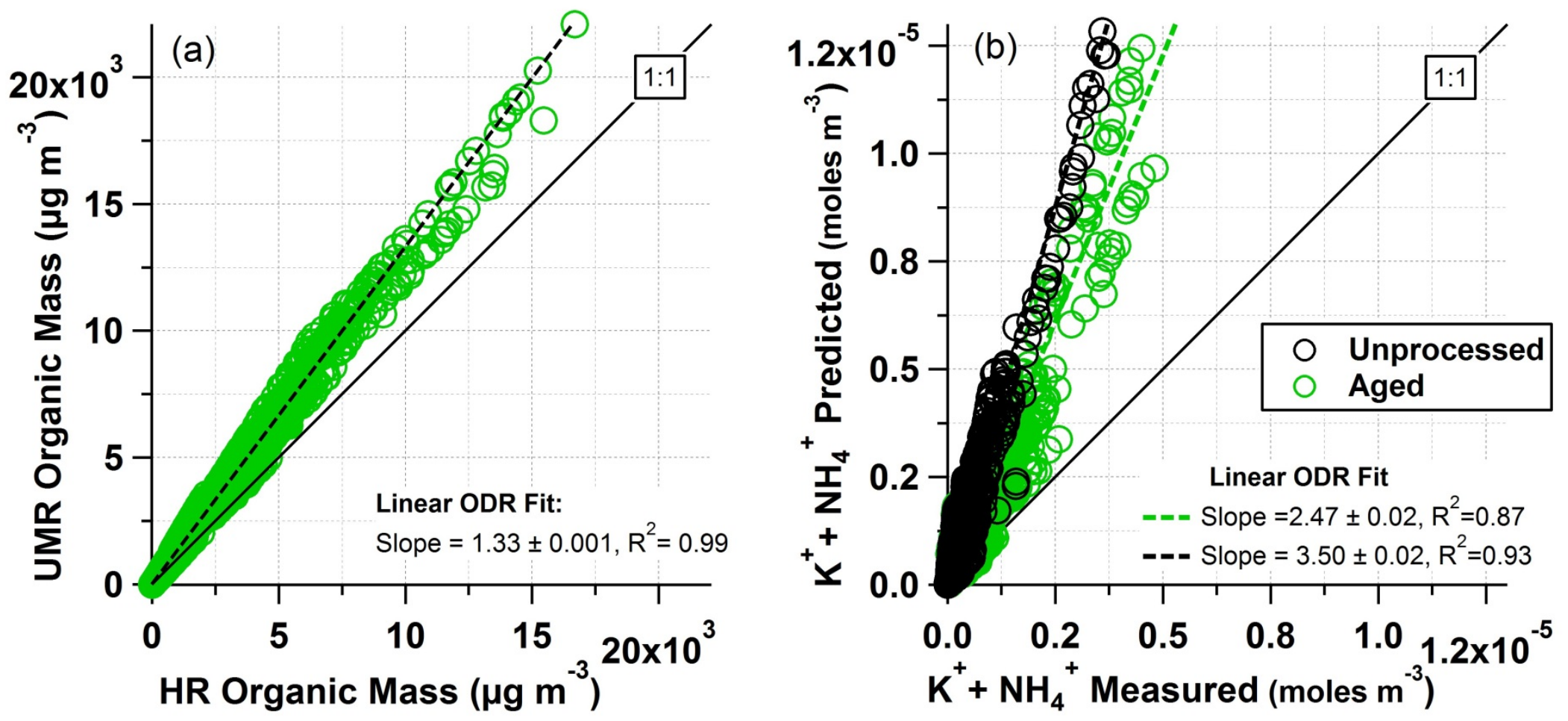
Figure S5.
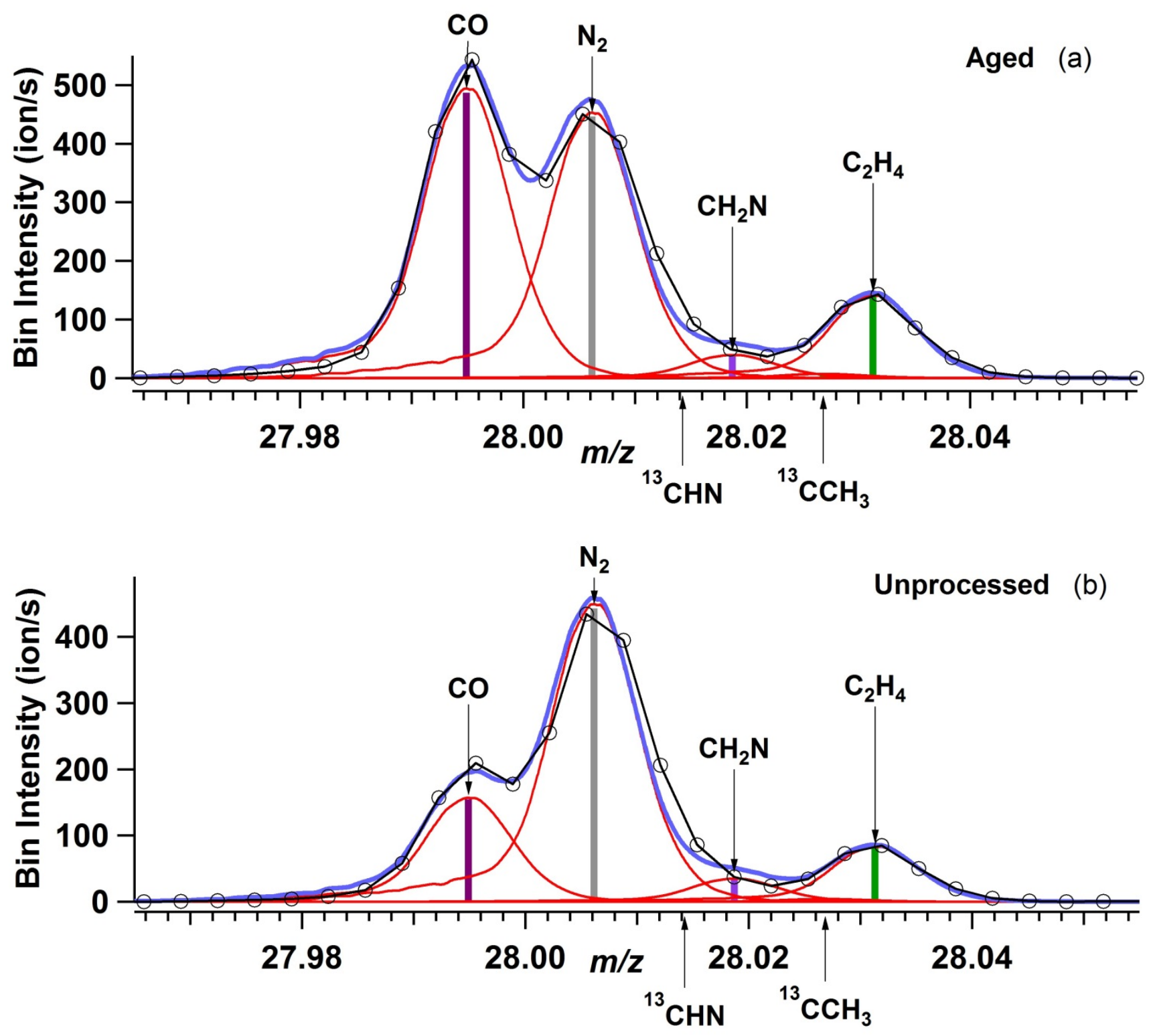
Figure S6.

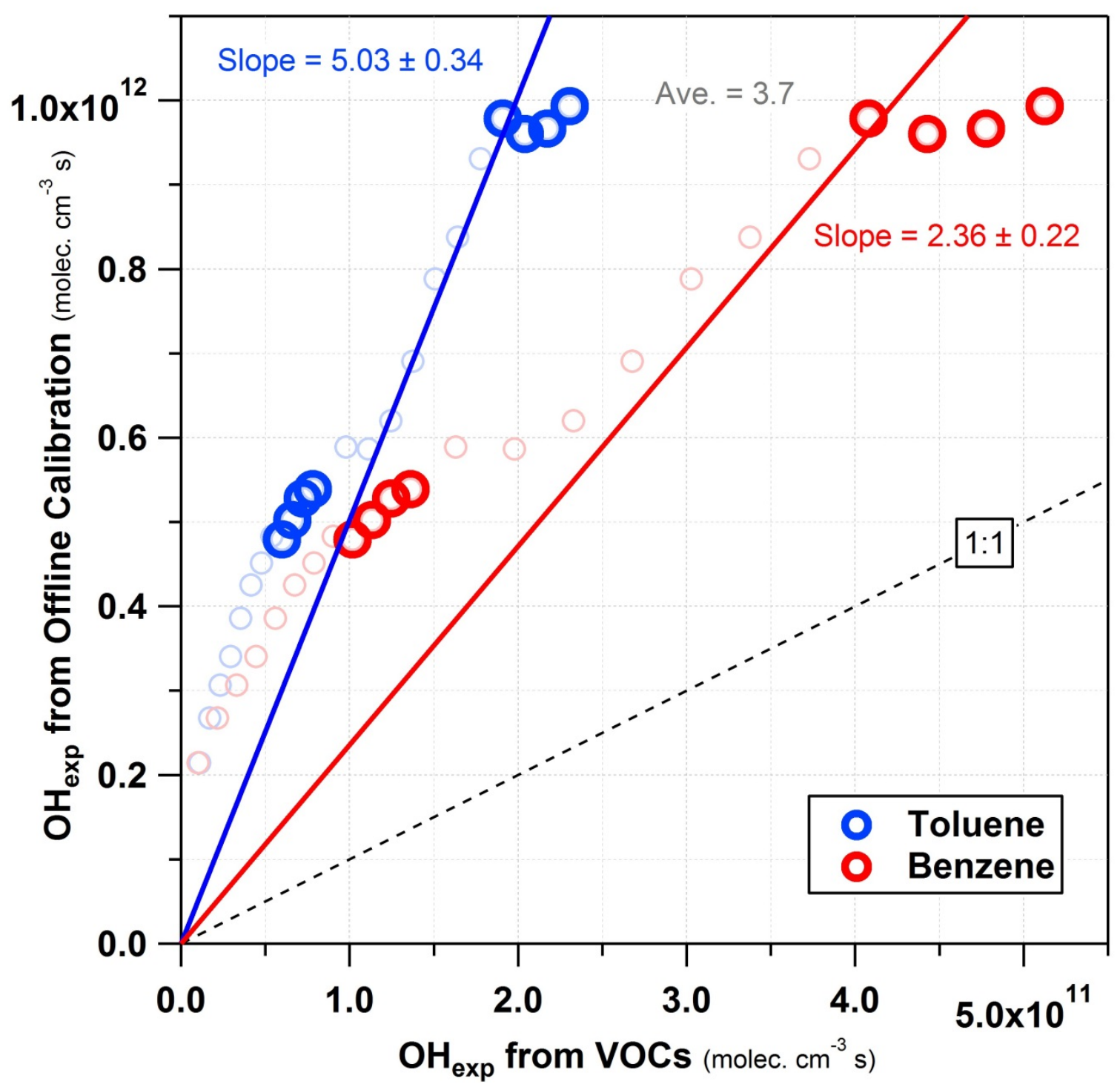




\section{Figure S7.}
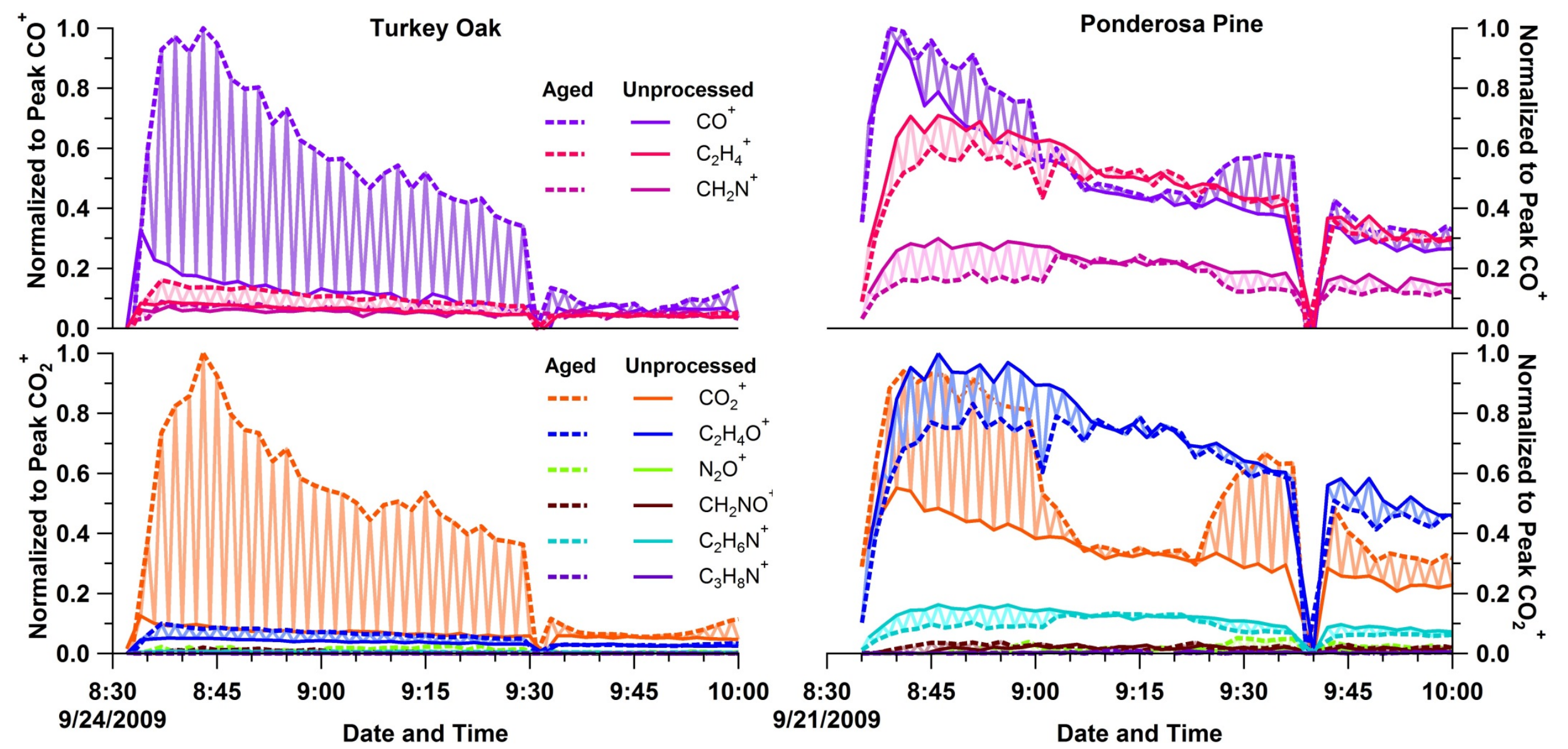
Figure S8.

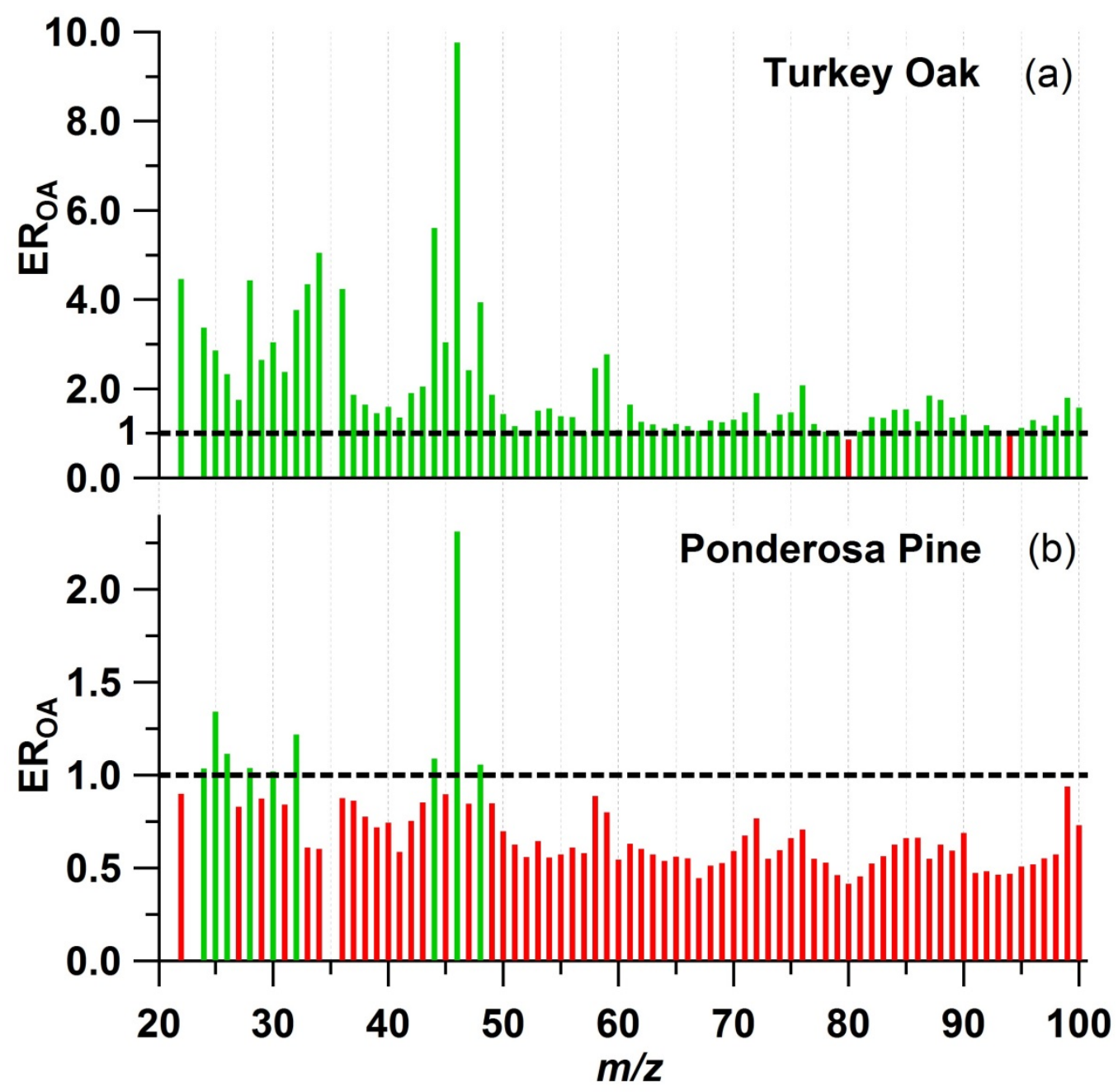


Figure S9.
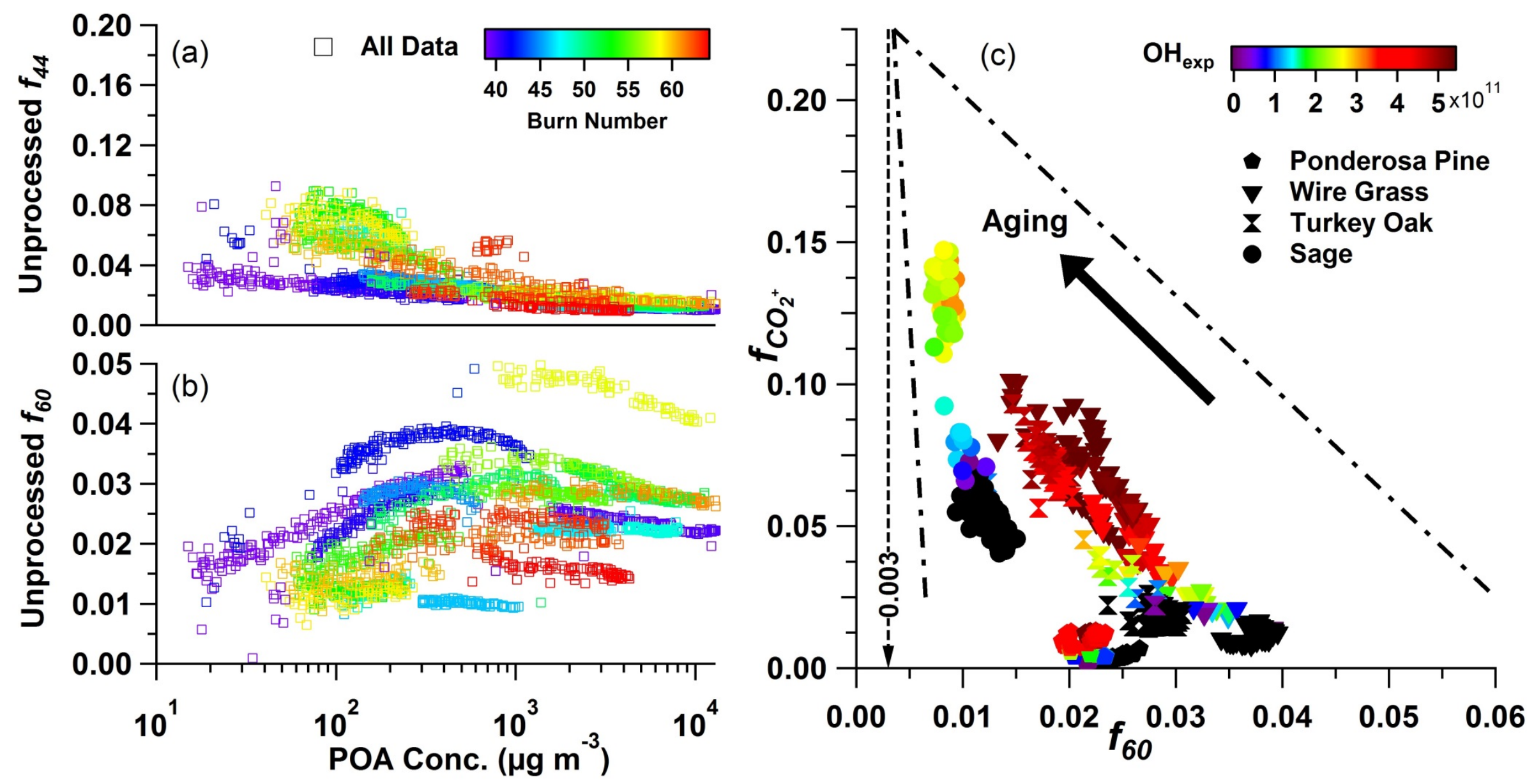
Figure S10.
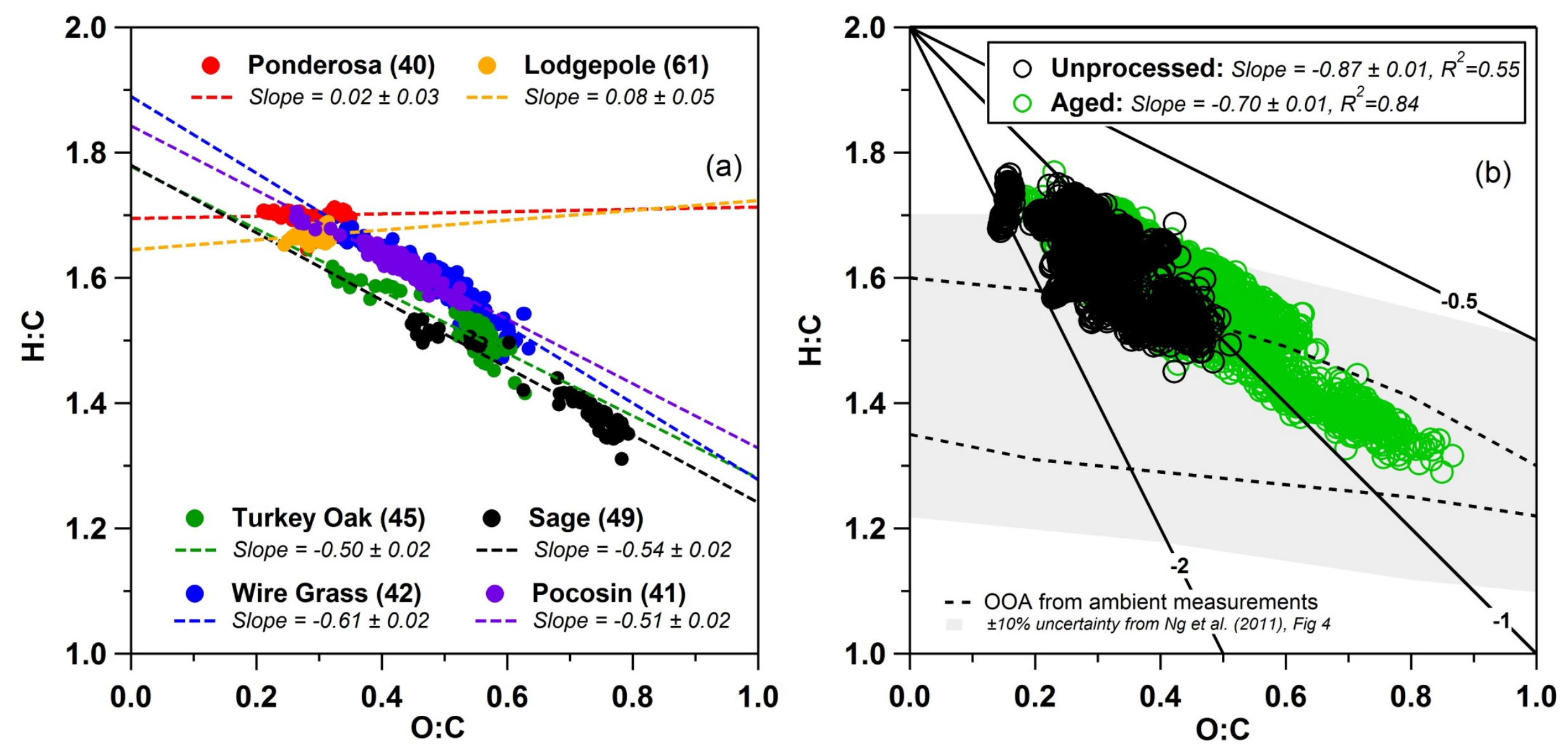